\title{
The homologue of the agrobacterial gene of cucumopine synthase is expressed in naturally transgenic peanuts
}

\author{
Bemova V.D. ${ }^{1 *}$, Matveeva T.V. ${ }^{2}$ \\ ${ }^{1}$ The N.I. Vavilov All-Russian Institute of Plant Genetic Resources (VIR), St. Petersburg, Russia \\ ${ }^{2}$ St. Petersburg State University, St. Petersburg, Russia \\ * email: viktoria.bemova@yandex.ru
}

Recent studies show that horizontal gene transfer from agrobacteria to plants occurs in evolution with a fairly high frequency: about 7 percent of dicotyledonous plant species are naturally transgeic. They contain homologues of Agrobacterium T-DNA genes in their genomes. The most common of them are opine synthesis genes. In naturally transgenic species Nicotiana tabacum and Cuscuta suaveolens the expression of opine synthase genes was revealed, and opines were identified in plant extracts. Their role in the control of plant-microbial interactions is discussed. The genomes of several species of the genus Arachis, contain homologues of agrobacterial cucumopine synthase (cus) and synthase of deoxyfructosylglutamine (mas2') genes. There are full-length cus genes with intact ORFs in A.duranensis, A. stenosperma, A. hypogaea and A. monticola. However, whether the gene is being expressed has remained to be unknown. Within the framework of this research, the expression of the cus gene in various organs of 9 lines of cultivated peanuts from the VIR collection was investigated. Studied lines have different morphological characteristics and geographic origins. Tissue-specific expression of the cus gene in peanut samples was revealed and lines contrasting in the level of its expression were found. The highest level of expression was observed in the roots. A preliminary assessment of economically valuable traits of peanuts (maturity, yield) when growing plants on nitrogen-rich soils does not show their relationship with the intensity of expression of the cus gene. It seems promising to assess these traits of peanut lines contrasting in expression of cus when cultivated on nitrogen-poor soils.

Acknowledgments: The research was made with support of the Russian Science Foundation grant No. 21-14-00050. 